\title{
Quadro de controle reprodutivo no manejo da propriedade leiteira
}

\author{
Lucio Pereira Rauber' ${ }^{1}$ Renan Farina² e Larissa Rafaeli Izolan²
}

Resumo - O gerenciamento reprodutivo através da anotação dos dados do rebanho possibilita identificar falhas de manejo, permitindo que medidas possam ser tomadas a fim de corrigi-las. O objetivo desta nota é apresentar o quadro de controle reprodutivo, tanto na forma física quanto virtual, para o gerenciamento de pequenas propriedades rurais produtoras de leite e explicar seu funcionamento. $\mathrm{O}$ quadro permite categorizar cada vaca de acordo com sua fase produtiva, facilitando a visualização do animal no rebanho e os cuidados que se deve ter em cada fase, o que permite alertar o produtor aos eventuais problemas reprodutivos. O quadro é acessível e aplicável à realidade das pequenas propriedades leiteiras de Santa Catarina.

Termos de indexação: Balde Cheio; deteç̧ão de cio; intervalo entre partos.

\section{Breeding Wheel in the dairy farm management}

Abstract - Reproductive management by recording herd data enables the identification of failures in the management, allowing corrective measures to be taken. The purpose of this note is to present the Breeding Wheel control framework, both in physical and virtual form, for the management of small dairy farms and to explain its functioning. The Wheel allows each cow to be categorized according to its productive phase, facilitating the visualization of the animal in the herd and the care procedures that must be taken in each phase, which makes it possible to alert the producer to possible reproductive problems. The framework is accessible and applicable to the reality of small dairy farms in Santa Catarina.

Index terms: Balde Cheio; estrus detection; calving interval.

\section{Introdução}

Pressupõe-se que as vacas devam parir em intervalos regulares de um ano, e é de conhecimento que os melhores índices de fertilidade são obtidos com serviços a partir dos sessenta dias pós-parto (LEITE et al., 2001; RIBEIRO et al., 2012), o que significa um período relativamente curto do parto à concepção. Algumas enfermidades puerperais e metabólicas, bem como deficiente detecção de cio, podem causar a baixa fertilidade, prolongando o intervalo parto-concepção e aumentando o descarte involuntário de animais (SANTOS \& RIBEIRO, 2014).

O gerenciamento reprodutivo possibilita identificar quais áreas do sistema de produção possuem deficiências, permitindo que medidas possam ser tomadas a fim de corrigilas (RIBEIRO et al., 2012; FARINA et al., 2017). Produtores com rebanhos maiores adotam tecnologias mais precisas como softwares de manejo de rebanho (GARGIULO et al., 2018).
Já os pequenos agricultores tendem a escolher tecnologias que tragam benefícios imediatos e que sejam fáceis de implementar (MARTíNEZ-GARCÍA et al., 2015).

A adoção de tecnologias permite que os agricultores tenham acesso a fontes de dados que podem ajudar a melhorar a saúde e o bem-estar do rebanho (BARKEMA et al., 2015). Os softwares de gerenciamento são as ferramentas mais utilizadas, porém a grande maioria trabalha em sistema de prestação de serviço ao produtor, tendo maior custo de manutenção apesar da eficiência. Além disso, os produtores e seus consultores devem ser treinados na interpretação de dados e no uso de listas de ação geradas por essas tecnologias (BARKEMA et al., 2015).

Tendo conhecimento disso, esta nota tem como objetivo apresentar uma opção simples de gerenciamento do rebanho leiteiro e, principalmente, aplicável às pequenas propriedades rurais de Santa Catarina.

\section{0 quadro ou roda da reprodução}

O quadro de controle reprodutivo (breeding wheel) é uma ferramenta simples e de baixo custo que foi adotada pelo programa "Balde Cheio", criado em 1998 (NOVO et al., 2017) pela Embrapa Pecuária Sudeste (SP). Entretanto, o programa ainda é pouco empregado em propriedades catarinenses. Lançado em 2016 (GESTÃO, 2016), o aplicativo para celular do quadro de controle reprodutivo está se popularizando, principalmente entre os jovens no meio rural.

\section{Como funciona}

O quadro possui uma base fixa e um círculo móvel central com divisões que correspondem aos meses e dias do ano (Figura 1A). Ele deve ser instalado em local com acesso diário do produtor, de forma que possa alimentá-lo e que sempre esteja atento às atividades com os animais. Os animais são divididos 
em quatro categorias: vacas paridas identificadas com ímã vermelho, vacas inseminadas com ímã amarelo, vacas prenhes com ímã azul e vacas secas com ímã verde. E ímã cinza para novilhas. O produtor escreve a identificação do animal no próprio ímã.

$\mathrm{Na}$ base fixa do quadro existem zonas nas cores vermelha, amarela, azul e verde correspondendo à categoria. $\mathrm{Na}$ zona vermelha da base encontramse os marcos "HOJE" referentes à data atual, e os marcos de 21, 42, 63 e 84 dias pós-parto (Figura 1B). A vaca entra no sistema recebendo o ímã vermelho no dia em que parir, sendo fixado na indicação "HOJE". A cada dia a roda gira no sentido horário, fazendo o animal progredir no quadro. Quando o animal atinge os marcos 21, 42, 63 e 84 pósparto, o produtor deve prestar atenção, pois eles se referem às possíveis datas para a vaca apresentar cio. Para uma vaca ter uma cria por ano, deve emprenhar em até 85 dias pós-parto, ou seja, ter até quatro inseminações. Portanto, é recomendado que um veterinário realize o exame ginecológico das vacas após o primeiro cio e antes de liberá-las para a primeira inseminação.

$\mathrm{Na}$ primeira inseminação a vaca tem o ímã trocado para a cor amarela e pula para o dia 84, indicado no quadro como "COBERTURA" (Figura 1C), independentemente da data da inseminação. Um ímã vermelho na faixa amarela indica que a vaca não foi vista em cio ou não foi inseminada, sugerindo a necessidade de um exame mais aprofundado. Ainda na faixa amarela, entre quarenta e sessenta dias após a inseminação, é indicado o momento de se fazer o diagnóstico de gestação das vacas que não retornaram ao cio.

A vaca com prenhez positiva recebe o ímã na cor azul, mesmo ainda estando na faixa amarela, e sem saltar no quadro. Sessenta dias pós-inseminação, a faixa da base do quadro passa a ser da cor azul. Um ímã amarelo na faixa azul indica que a vaca não passou pelo diagnóstico de gestação. O ímã azul permanece até sessenta dias antes do parto, marco no qual a vaca passa a usar o ímã da cor verde e onde o quadro indica que ela deve ser seca. A faixa verde também indica, trinta dias antes do parto, o momento de realizar

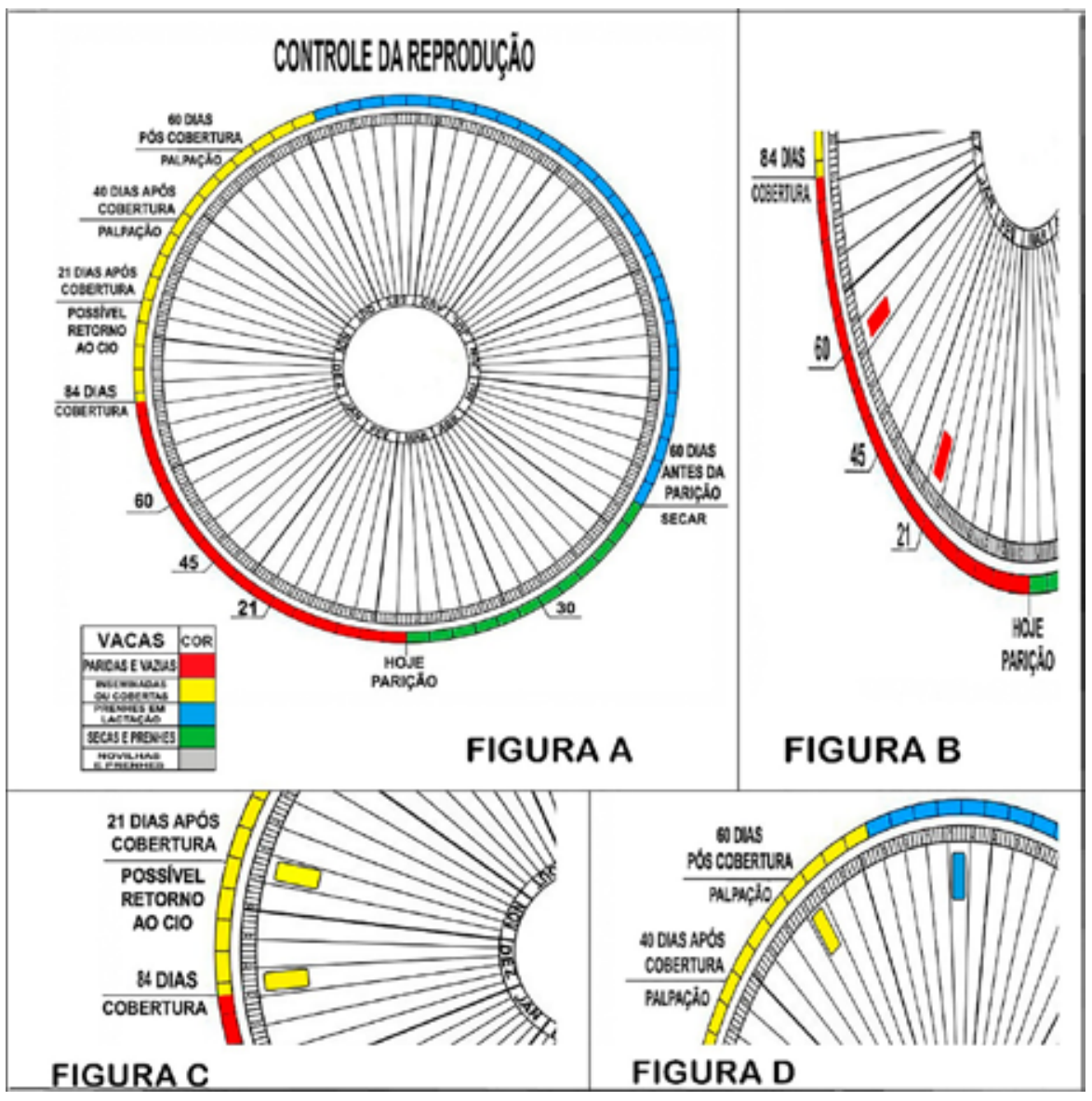

Figura 1. Representação do quadro de controle reprodutivo

Figure 1. Representation of the reproductive control chart

os manejos pré-parto.

Após o parto fecha-se o ciclo, e a vaca volta a receber o ímã vermelho. As novilhas, que têm sua gestação confirmada, recebem um ímã na cor cinza que é fixado junto à data em que ocorreu a inseminação. O quadro mostra-se eficiente dentro das pequenas propriedades leiteiras pois é uma ferramenta que pode ser manuseada por qualquer pessoa que esteja envolvida na rotina do rebanho.

\section{Pontos críticos}

O salto que a vaca faz para o dia 84 causado pela inseminação pode gerar confusão. Com esta manobra, não fica mais visível os "dias em aberto", ou seja, a contagem dos dias em que a vaca está vazia. Outra falha é referente ao número de inseminações realizadas. Se a vaca retornar ao cio e for inseminada novamente, ela também volta para o dia 84 e o produtor pode perder a contagem de quantas inseminações foram necessárias para emprenhar o animal.

Por isso é tão importante que o produtor mantenha todos os dados e eventos anotados em uma caderneta ou planilha. Os índices como "dias em aberto", "dias em leite", "número de inseminações por concepção" e "intervalo entre partos" não são calculados pelo quadro. Para tanto, o produtor deve ter os dados como dia do parto, dia dos cios, das inseminações e diagnóstico de gestação anotados. Fichas individuais para cada animal devem ser implantadas na propriedade e estas podem variar de acordo com a necessidade.

\section{Plataforma digital "Roda da Reprodução"}

No intuito de ampliar o uso da metodologia de gerenciamento do rebanho leiteiro, em 2016 a Embrapa 
Pecuária Sudeste (SP) lançou o aplicativo gratuito de celular "Roda da Reprodução", seguindo os mesmos moldes do quadro físico (GESTÃO, 2016). O aplicativo já foi instalado em mais de 10 mil aparelhos e possui excelente avaliação pelos usuários. Em 2018 o aplicativo foi atualizado e incorporada a ferramenta "Roda do Crescimento" onde o produtor pode lançar os dados das bezerras. Nesta versão ainda há a opção de importar os dados de outras bases, facilitando a inserção do rebanho no aplicativo.

O aplicativo é de fácil manuseio e oferece funcionalidades como agenda para cadastro dos animais, controle do ciclo dos estágios produtivo e reprodutivo. Basta consultar os animais cadastrados, incluir filtros de pesquisa por categoria e compartilhar as informações com empregados ou outros produtores por e-mail ou programas de mensagem (GESTÃO, 2016). No entanto, alguns pontos poderiam ser melhorados, como um login virtual e a possibilidade de fazer backup das informações do rebanho em um banco de dados disponível ao produtor em outras plataformas digitais a fim de assegurar as informações do rebanho. Observou-se também a ausência de notificações de atividades a serem realizadas em determinado dia, como possível retorno ao cio, diagnóstico de gestação, secagem e provável data do parto. Sem contar que o produtor deve ter um aparelho eletrônico que suporte o programa, bem como acesso à internet e conhecimento básico para usá-lo.

O aplicativo "Roda da Reprodução" é uma alternativa eficiente e viável para gerenciar os dados do manejo, possibilita maior facilidade de registro e portabilidade, além de acesso rápido ao histórico de cada animal da propriedade e o envio das informações ao técnico ou veterinário. O quadro de controle reprodutivo gera uma informação visual, fazendo com que o produtor foque a atenção nos eventos e animais, é de baixo custo, de fácil manuseio e compreensão, entretanto, não dispensa o uso das anotações.

\section{Referências}

BARKEMA, H.W.; VON KEYSERLINGK, M.A.; KASTELIC, J.P.; LAM, T.J.; LUBY, C.; ROY, J.P.; LEBLANC, S.J.; KEEFE, G.P.; KELTON, D.F. Invited review: changes in the dairy industry affecting dairy cattle health and welfare. Journal of Dairy Science, Champaign, v. 98, n. 11, p. 7426-7445, 2015.

FARINA, R.; SECCO, R.; SPAGNOL, A.B.; FRIGO, M.E.; PIVATTO, R.A.; PAPPEN, F.G.; RAUBER, L.P. Implantação do Quadro Reprodutivo no setor de zootecnia do IFC campus Concórdia. In: SIMPÓSIO DO LEITE - 8o FÓRUM NACIONAL DE LÁCTEOS - 6a MOSTRA DE TRABALHOS CIENTÍFICOS, 14., 2017, Erechim. Anais [...]. Erechim: Simpósio do Leite, 2017. p. 1-3.

GARGIULO, J.I.; EASTWOOD, C.R.; GARCIA, S.C.; LYONS, N.A. Dairy farmers with larger herd sizes adopt more precision dairy technologies. Journal of Dairy Sciences, Champaign, v. 101, n. 6, p. 5466-5473, 2018.

EMBRAPA. GESTÃO do rebanho leiteiro ganha aplicativo. Embrapa. Brasília, DF. 23 ago. 2016. Disponível em: https://bit. Iy/2cLeLqi. Acesso em: 18 ago. 2017.

LEITE, T.E.; MORAES, J.C.F.; PIMENTEL, C.A. Eficiência produtiva e reprodutiva em vacas leiteiras. Ciência Rural, Santa Maria, v. 31, n. 3, p. 467-472, 2001.

MARTÍNEZ-GARCÍA, C.G.; UGORETZ, S.J.; ARRIAGA-JORDÁN, C.M.; WATTIAUX, M.A. Farm, household, and farmer characteristics associated with changes in management practices and technology adoption among dairy smallholders. Tropical Animal Health and Production, v.47, p.311-316, 2015.

NOVO, A.L.M.; CAMARGO, A.C.; MORI, C.; PALHARES, J.C.P.; VINHOLIS, M.M.B.; BARIONI JÚNIOR, W. Relatório 2016: Dados zootécnicos, econômicos e de uso de tecnologia, Projeto Balde Cheio - Minas Gerais. São Carlos: Embrapa Pecuária Sudeste, 2017. 63 p.

RIBEIRO E.S.; GALVÃO K.N.; THATCHER W.W.; SANTOS J.E.P. Economics aspects of dairy reproductive Technologies to dairy herds. Animal Reproduction, Belo Horizonte, v. 9, n. 3, p.370-387, 2012.

SANTOS, J.E.P.; RIBEIRO, E.S.; Impact of animal health on reproduction of dairy cows. Animal Reproduction, Belo Horizonte, v. 11, n. 3, p.254-269, 2014 .

\section{Năo deire sua consciência escorrer pelo ralo: preserve a água e evite o desperdício.}

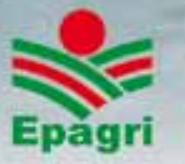

